\title{
Retailer's Joint Ordering, Pricing, and Preservation Technology Investment Policies for a Deteriorating Item under Permissible Delay in Payments
}

\author{
Umakanta Mishra $\mathbb{D}^{1},{ }^{1,2}$ Jacobo Tijerina-Aguilera, ${ }^{1}$ \\ Sunil Tiwari, ${ }^{3}$ and Leopoldo Eduardo Cárdenas-Barrón $\left.{ }^{4}\right)^{4}$ \\ ${ }^{1}$ Universidad de Monterrey, Av. Ignacio Morones Prieto 4500 Pte., 66238 San Pedro Garza García, NL, Mexico \\ ${ }^{2}$ Faculty of Science \& Technology, ICFAI University, Tripura, Kamalghat, Sadar, West Tripura, Tripura 799210, India \\ ${ }^{3}$ The Logistics Institute-Asia Pacific, National University of Singapore, 21 Heng Mui Keng Terrace, No. 04-01, Singapore 119613 \\ ${ }^{4}$ School of Engineering and Sciences, Tecnológico de Monterrey, E. Garza Sada 2501 Sur, CP 64849, Monterrey, NL, Mexico \\ Correspondence should be addressed to Leopoldo Eduardo Cárdenas-Barrón; lecarden@itesm.mx
}

Received 11 September 2017; Revised 8 January 2018; Accepted 15 January 2018; Published 21 February 2018

Academic Editor: Emilio Turco

Copyright (C) 2018 Umakanta Mishra et al. This is an open access article distributed under the Creative Commons Attribution License, which permits unrestricted use, distribution, and reproduction in any medium, provided the original work is properly cited.

\begin{abstract}
This article develops an inventory model for deteriorating items with controllable deterioration rate (by using preservation technology) under trade credit policy. As in practical scenarios the demand of an item is directly associated with its selling price, keeping this in mind, it is assumed to be a price dependent demand. The main objective of the inventory model is to determine jointly the optimal ordering, pricing, and preservation technology investment policies for retailer so that the total profit is maximized. The effects of key parameters on optimal solution are studied through a sensitivity analysis with the aim of examining the behavior of the inventory model with controllable deterioration under the permissible delay in payments.
\end{abstract}

\section{Introduction}

Inventory control is the activity which organizes the availability of items to the customers. On the one hand, storing large quantities is not a right solution for stockout condition and for meeting the demand of consumers. On the other hand, most of products are deteriorating in nature and the deterioration process cannot be stopped but it can be controlled with the aim of delaying the speed of the deterioration.

It is well known that the profit can be increased by increasing sales or reducing costs. Longer trade credit period can cause sales making the demand increase, and the consequent rise in the ordering quantity produces a larger deterioration cost. The natural process of deterioration can be able to stop; it may be reduced by specific processes when products are at risk of deterioration. For example, cold storage reduces the deterioration of sea products and seasonal products. Hence, the degree of deterioration of the items depends on the investment in the preservation technology of the inventory at the facility as well as the environmental conditions. Due to advancement in technologies nowadays one can slow down the deterioration rate of items by investing money on preservation technology. It is well known that Ghare and Schrader [1] developed the first inventory model for deteriorating items. Recently, many researchers have studied the effect of preservation technology investment on reducing item's deterioration. For example, Hsu et al. [2] were the first ones who investigated the impact of preservation technology investment on an exponentially decaying inventory model involving partial backorders. Later, Lee and Dye [3] and Dye and Hsieh [4] established an inventory model for a deteriorating item under the usage of preservation technology considering different scenarios. Afterwards, Dye [5] explored the effect of preservation technology investment 
on a noninstantaneously deteriorating item. Subsequently, Zhang et al. [6] and Liu et al. [7] studied the characteristics of preservation technology investment for deteriorating items. Yang et al. [8] investigated the tradeoff between preservation technology investment and the optimal dynamic trade credit for a deteriorating inventory model. After, Tsao [9] extended the inventory model of Dye [5] to consider a joint location and preservation technology investment decisionmaking problem for noninstantaneous deteriorating items taking into consideration trade credit. Recently, Mishra et al. [10] studied the characteristics of preservation technology investment for deteriorating items with price dependent demand.

In real life business via share marketing, trade credit financing becomes an influential tool to improve sales and reduce on-hand stock. The permissible delay in payments reduces the cost of holding stock since it reduces the amount of capital invested in stock for the duration of the permissible period. Furthermore, during the delay period, the buyer can accumulate revenue on sales and earn interest on that revenue via share market investment or banking business. It gives economic sense for the retailer to accept the delay period allowed by the supplier. In addition, trade credit offered by the supplier encourages a lot the retailer to buy more products. Hence, the trade credit plays a major role in inventory control for both supplier and retailer.

The fact that trade credit allows retailers to increase the size of their orders makes it an important issue in supply chain management. Perhaps, Goyal [11] was the first to develop an economic order quantity (EOQ) inventory model with permissible delay in payment. The inventory model proposed by Goyal [11] has attracted the attention of several researchers and academicians. For example, Jaggi and Aggarwal [12] extended Goyal's [11] inventory model to perishable items using the discounted cash-flows (DCF) approach to determine the optimum order quantity in situations of trade credit. In a subsequent paper, Aggarwal and Jaggi [13] extended Goyal's [11] inventory model for deteriorating items. After, Jamal et al. [14] developed an optimal ordering policy for perishable items under conditions of permissible delays in payment and allowable shortages. Later, Chung [15] revisited Goyal's [11] inventory model and he proposed an alternative solution procedure. Afterwards, Jamal et al. [16] further extended Goyal's [11] inventory model to allowable shortages. Then Teng [17] modified Goyal's [11] inventory model by considering different unit price and unit cost. Through his model, Teng [17] justified that it is more beneficial for a buyer (in economical point) to order less quantity and take the benefits of delay in payments more frequently. Subsequently, Chang [18] built an EOQ inventory model for perishable items under inflation in cases where supplier credit is linked to order quantity. Next, Chang et al. [19] determined that delays in payment depend on the quantity ordered. They also concluded that a fixed trade credit period is permissible when the order quantity exceeds the quantity at which the delay payment is permitted; otherwise, the retailer must pay for the item immediately. Huang [20] developed an inventory model to determine the optimal order quantity considering permissible delays in payment in cases where the order quantity is below a predetermined quantity. After that, Chung and Huang [21] presented a more comprehensive inventory model in which the total variable cost was shown to include various forms of convexity. Next, Chang et al. [19] determined that delays in payment depend on the quantity ordered. They also concluded that a fixed trade credit period is permissible when the order quantity exceeds the quantity at which the delay payment is permitted; otherwise, the retailer must pay for the item immediately. Chung and Lin [22] developed a simple algorithm to overcome the shortcomings of Jaggi and Aggarwal's [12] inventory model. Geetha and Udayakumar [23] built an inventory model for deteriorating items considering trade credit financing when the demand is a linear function of time. Optimal solution procedures to find the optimal order quantity and cycle time are discussed. The literature on trade credit is vast; the following research works are worth mentioning: Liao [24], Jaggi et al. [25], Teng [26], Teng and Chang [27], Chang et al. [28, 29], Teng et al. [30], Teng et al. [31], Teng et al. [32], Chung et al. [33], Ouyang and Chang [34], Ouyang et al. [35], Khanra et al. [36], Chen et al. [37], Wu and Chan [38], Chen and Teng [39], Geetha and Udayakumar [23], Chang et al. [40], Wu et al. [41], Zhou et al. [42], Tiwari et al. [43], Giri and Sharma [44], Jaggi et al. [45, 46], Mahata and De [47], and Wu et al. [48]. For an extensive and updated review of the trade credit literature, the reader can read the papers of Seifert et al. [49] and Molamohamadi et al. [50].

The aim of this study is to provide a solution for the inventory and preservation effort problem under trade credits. The contributions of this work to the literature are as follows. First, this is the first study to consider inventory decisionmaking problem for deteriorating items with price dependent demand under trade credits. Second, this study also considers the preservation effort decision. This copes with more practical situations. Therefore, this paper studies the retailer's replenishment and pricing policies for a deteriorating item where retailer invests money on preservation technology in order to reduce the deterioration rate when supplier provides a credit period to retailer for settling the amount. The consequences of price dependent demand, preservation technology investment, and trade credit are incorporated into the traditional deteriorating inventory model. The main objective of this paper is to find the optimal replenishment, pricing, and preservation technology investments strategies which maximize the total profit. Table 1 shows a comparison of some recent works related to preservation technology.

The rest of the paper is organized as follows. Section 2 provides notation, assumptions, and the mathematical formulation for the inventory model with controllable deterioration under the permissible delay in payments. Section 3 proposes a solution procedure for maximizing the total profit. Section 4 illustrates the inventory model with the help of numerical examples. Section 5 presents a sensitivity analysis of the optimal solution with respect to some parameters of the inventory system. Section 6 gives some conclusions and establishes suggestions for future research. 
TABLE 1: Comparison of some existing literature on preservation technology.

\begin{tabular}{lccc}
\hline Authors & Demand type & Trade credit & Preservation technology \\
\hline Hsu et al. [2] & Constant demand & No & Yes \\
Dye et al. (2012) & Constant demand & No & Yes \\
Dye [5] & Constant demand & No & Yes \\
He and Huang [51] & Price dependent & No & Yes \\
Zhang et al. [6] & Price dependent & No & Yes \\
Yang et al. [8] & Time dependent & Yes & Yes \\
Tsao [9] & Poisson distributed & No & Yes \\
Mishra et al. [10] & Price dependent & No & Yes \\
This paper & Price dependent & Yes & Yes \\
\hline
\end{tabular}

\section{Mathematical Formulation of the Inventory Model with Controllable Deterioration under the Permissible Delay in Payments}

2.1. Notation. The notation that is used in the development of the inventor model is shown below.

\section{Parameters}

$\lambda(\alpha)$ : deterioration rate when there is an investment on preservation technology (units/time unit)

$\lambda_{0}$ : deterioration rate without preservation technology investment (units/time unit)

$\delta$ : sensitive parameter of investment to the deterioration rate

$D(p)=a-b p$ : demand rate function which is a function of selling price $p$ (units/time unit)

a: demand scale

$b$ : price sensitive parameter

$C$ : purchasing cost (\$/unit)

$h$ : inventory holding cost (\$/unit/time unit)

$A$ : ordering cost per order (\$/order)

$M$ : credit period offered by supplier (time unit)

$I_{e}$ : the interest earned by the retailer (\%/time unit)

$I_{p}$ : the interest payable by the retailer (\%/time unit)

$I(t)$ : inventory level (units)

$\mathrm{TP}(T, \alpha, p)$ : total profit (\$/time unit)

\section{Dependent Decision Variables}

Q: ordering quantity (units)

\section{Decision Variables}

$T$ : inventory cycle length (time unit)

$\alpha$ : cost of preservation technology investment per unit time (\$/unit/time unit)

$p$ : selling price (\$/unit).
2.2. Assumptions. The inventory model with controllable deterioration under the permissible delay in payments is based on the following assumptions.

(i) The demand rate, $D(p)=a-b p$, is assumed to be price dependent, where $a$ and $b$ are nonnegative constants.

(ii) The inventory planning horizon is infinite and the inventory system involves only one item.

(iii) It is considered the assumption of He and Huang [51] which is as follows: $\lambda(\alpha)=\lambda_{0} e^{-\delta \alpha}$, where $\lambda(\alpha)$ is the deterioration rate after investing on preservation technology, $\lambda_{0}$ is the deterioration rate without preservation technology investment, and $\delta$ is the sensitive parameter of investment to the deterioration rate. The relationship of deterioration rate and the preservation technology investment parameter satisfies the following conditions: $\partial \lambda(\alpha) / \partial \alpha<0, \partial^{2} \lambda(\alpha) / \partial \alpha>0$.

(iv) The cost of preservation technology investment per unit time is constrained to $\alpha \in[0, \bar{\alpha}]$.

(v) There is no shortage of inventory.

(vi) Under a trade credit period $M$, the retailer would settle the account at time $t=M$ and pays for the interest charge on items in stock with rate $I_{p}$ over the interval $[M, T]$ as $T \geq M$. Alternatively, when the retailer settles the account at time $t=M$, it is not required to pay any interest charge for items in the stock during the whole cycle as $T \leq M$.

(vii) The retailer accumulates revenue and earns interest from the beginning of the inventory cycle until the end of the trade credit period offered by the supplier. That is, the retailer collects revenue and receives interest during the period from $t=0$ to $t=M$ with rate $I_{e}$ under trade credit conditions.

2.3. Inventory Model with Controllable Deterioration under the Permissible Delay in Payments. Figure 1 shows the inventory level through time. The inventory model is described briefly as follows: the retailer orders and receives an order size of $Q$ units of a single product from the supplier at the beginning of the cycle, that is, at time $t=0$. During the time interval $[0, T]$, the inventory level $I(t)$ is depleted gradually due to demand from the customers. At time $t=T$, the inventory level drops to zero. 


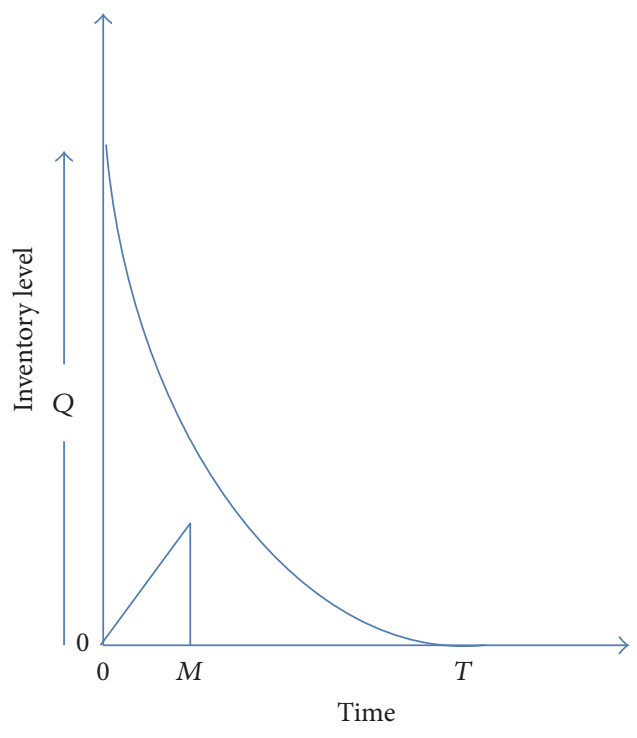

Case 1: $M \leq T$

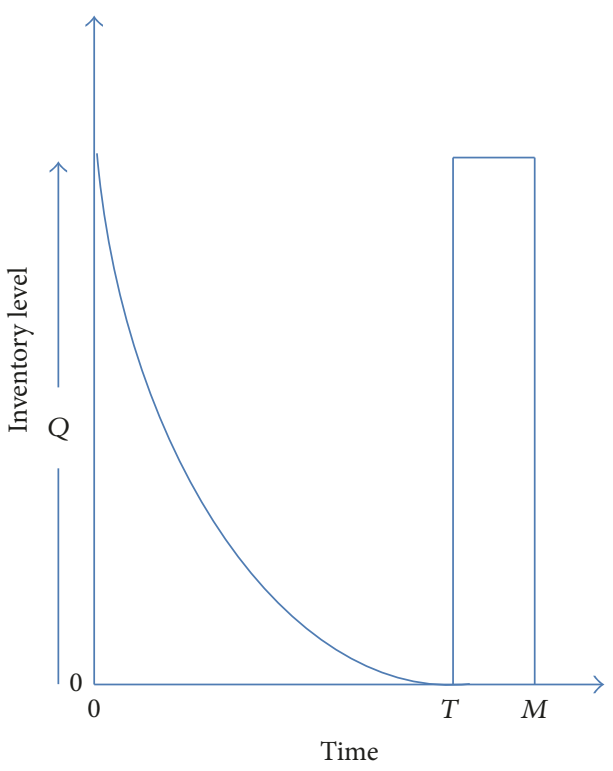

Case 2: $M \geq T$

FIGURE 1: Graphical representation of the inventory behavior through time.

The differential equation representing the change of inventory level $I(t)$ with respect to time is as follows:

$$
\frac{d I(t)}{d t}+\lambda(\alpha) I(t)=-D(p), \quad 0 \leq t \leq T
$$

Considering the initial condition $I(0)=Q$ and the boundary condition $I(T)=0$, hence the solution to the differential equation (1) is

$$
I(t)=\frac{D(p)}{\lambda(\alpha)}\left[e^{\lambda(\alpha)(T-t)}-1\right], \quad 0 \leq t \leq T .
$$

Thus, the retailer's order size per cycle is given by

$$
I(0)=Q=\frac{D(p)}{\lambda(\alpha)}\left[e^{\lambda(\alpha) T}-1\right]
$$

The retailer's profit function per cycle is comprised of the elements listed below:

(a) The total sales revenue $=p D(p)$.

(b) Ordering cost $=A$

(c) Purchasing cost $=C Q=(C D(p) / \lambda(\alpha))\left[e^{\lambda(\alpha) T}-1\right]$.

(d) Inventory holding cost $=h \int_{0}^{T} I(t) d t=(h D(p) /$ $\left.\lambda^{2}(\alpha)\right)\left[e^{\lambda(\alpha) T}-1-\lambda(\alpha) T\right]$.

(e) Preservation technology cost $=\alpha$.

(f) Interest payable: depending on the retailer's trade credit period $M$ offered by the supplier, the following two cases occur: Case 1 when $M \leq T$ and Case 2 when $M \geq T$ which are shown in Figure 1. Thus, to compute the interest payable, we need to consider these two cases. The calculation of interest payableis detailed below.
Case $1(M \leq T)$. When the credit period $M$ is less than or equal to the replenishment cycle time $T$, the retailer begins to pay interest for the items in stock after time $M$ with a rate $I_{p}$. Hence, the interest payable is calculated as follows:

$$
I_{p} C \int_{M}^{T} D(p)(T-t) d t=\frac{I_{p} C D(p)}{2}(T-M)^{2}
$$

Case $2(M \geq T)$. Because $T$ is less than or equal to the credit period $M$, there is no interest paid for financing the inventory in stock. Therefore, the interest payable in this case is zero.

(g) Interest earned: to compute the interest earned, it is necessary to consider the two mentioned cases above.

Case $1(M \leq T)$. In this case, the retailer sells the goods, accumulates sales revenue, and earns interest with rate $I_{e}$ until time $M$. Therefore, the interest earned from time 0 to $M$ per cycle is computed with

$$
I_{e} p \int_{0}^{T} D(p)(T-t) d t=I_{e} p D(p)\left(\frac{T^{2}}{2}\right) .
$$

Case $2(M \geq T)$. Because the cycle time $T$ is less than or equal to the credit period $M$, from time 0 to $T$, the retailer sells the goods and continues to accumulate sales revenue to earn interest. Therefore, the interest earned from time 0 to $M$ per cycle is determined as

$$
D(p) I_{e} p T\left(M-\frac{T}{2}\right)
$$


Hence, the total profit per unit time is given by

$$
\begin{aligned}
& \mathrm{TP}(T, \alpha, p)=\text { sales revenue }-\frac{1}{T} \text { [ordering cost } \\
& + \text { purchasing cost }+ \text { inventory holding cost } \\
& + \text { preservation technology cost }+ \text { interest payable } \\
& \text { - interest earned] }
\end{aligned}
$$$$
\operatorname{TP}(T, \alpha, p)= \begin{cases}\mathrm{TP}_{1}(T, \alpha, p) & \text { if } M \leq T \\ \operatorname{TP}_{2}(T, \alpha, p) & \text { if } M \geq T\end{cases}
$$

In (8), $\mathrm{TP}_{1}(T, \alpha, p)$ and $\mathrm{TP}_{2}(T, \alpha, p)$ represent the total profit per unit time when $M \leq T$ and $M \geq T$, respectively, where

$$
\begin{aligned}
\mathrm{TP}_{1}(T, \alpha, p)=p D(p)-\frac{1}{T}[A \\
+\frac{C D(p)}{\lambda(\alpha)}\left[e^{\lambda(\alpha) T}-1\right] \\
+\frac{h D(p)}{\lambda^{2}(\alpha)}\left[e^{\lambda(\alpha) T}-1-\lambda(\alpha) T\right]+\alpha \\
\left.+\frac{I_{p} C D(p)}{2}(T-M)^{2}-I_{e} p D(p)\left(\frac{T^{2}}{2}\right)\right] \\
\mathrm{TP}_{2}(T, \alpha, p)=p D(p)-\frac{1}{T}[A \\
+\frac{C D(p)}{\lambda(\alpha)}\left[e^{\lambda(\alpha) T}-1\right] \\
+\frac{h D(p)}{\lambda^{2}(\alpha)}\left[e^{\lambda(\alpha) T}-1-\lambda(\alpha) T\right]+\alpha \\
-
\end{aligned}
$$

It is easy to verify that $\operatorname{TP}_{1}(M, \alpha, p)=\operatorname{TP}_{2}(M, \alpha, p)$ when $T=M$. In the following section, we determined the optimal solution of the inventory model for the two cases: namely, $M \leq T$ and $M \geq T$.

\section{Optimal Solution Procedure}

This section determines the optimum values of $T, \alpha$, and $p$ which maximize the total profit $\operatorname{TP}(T, \alpha, p)$. The necessary conditions to maximize the total profit are proved by following propositions.

Proposition 1. When $\alpha$ and $p$ are fixed, the total profit is concave with respect to $T$.
Proof. The first- and second-order partial derivatives of the total profit with respect to $T$ are as follows:

$$
\begin{aligned}
& \frac{\partial \mathrm{TP}_{1}(T, \alpha, p)}{\partial T}=\frac{A+\alpha}{T^{2}} \\
& -\frac{C D(p)}{2 T^{2}}\left[\left\{2 T(T-M)-(T-M)^{2}\right\} I_{p}+T^{2} I_{e}\right. \\
& \left.-T\left\{e^{e^{-\alpha \delta T \lambda_{0}}}-\frac{e^{\alpha \delta}\left(-1+e^{e^{-\alpha \delta T \lambda_{0}}}\right)}{\lambda_{0}}\right\}\right] \\
& -\frac{h D(p)}{T^{2} \lambda_{0}}\left[T e^{2 \alpha \delta}\left(-e^{-\alpha \delta} \lambda_{0}+e^{-\alpha \delta+e^{-\alpha \delta} T \lambda_{0}} \lambda_{0}\right)\right. \\
& \left.-e^{2 \alpha \delta}\left(-1-T e^{-\alpha \delta} \lambda_{0}+e^{-\alpha \delta+e^{-\alpha \delta} T \lambda_{0}}\right)\right], \\
& \frac{\partial^{2} \mathrm{TP}_{1}(T, \alpha, p)}{\partial T^{2}}=-\frac{2(A+\alpha)}{T^{3}}-\frac{1}{2} C D(p)\left[\frac{2}{T}\right. \\
& \left.-\frac{4(T-M)}{T^{2}}+\frac{2(T-M)^{2}}{T^{3}}\right] I_{p}-C D(p) \\
& {\left[-\frac{2 e^{e^{-\alpha \delta} T \lambda_{0}}}{T^{2}}+\frac{2 e^{\alpha \delta}\left(e^{e^{-\alpha \delta} T \lambda_{0}}-1\right)}{T^{3} \lambda_{0}}\right.} \\
& \left.+\frac{e^{-\alpha \delta+e^{-\alpha \delta} T \lambda_{0}} \lambda_{0}}{T}\right]-h D(p)\left[\frac{e^{e^{-\alpha \delta} T \lambda_{0}} h}{T}\right. \\
& -\frac{2 e^{2 \alpha \delta} h\left(e^{-\alpha \delta+e^{-\alpha \delta} T \lambda_{0}} \lambda_{0}-e^{-\alpha \delta} \lambda_{0}\right)}{T^{2} \lambda_{0}^{2}} \\
& \left.+\frac{2 e^{2 \alpha \delta} h\left(e^{e^{-\alpha \delta} T \lambda_{0}}-e^{-\alpha \delta} T \lambda_{0}-1\right)}{T^{3} \lambda_{0}^{2}}\right]<0 .
\end{aligned}
$$

Therefore, for an optimum solution, it is considered that $\partial \mathrm{TP}_{1}(T, \alpha, p) / \partial T=0$

$$
\begin{aligned}
& \frac{\partial \mathrm{TP}_{1}(T, \alpha, p)}{\partial T}=\frac{A+\alpha}{T^{2}} \\
& -\frac{C D(p)}{2 T^{2}}\left[\left\{2 T(T-M)-(T-M)^{2}\right\} I_{p}+T^{2} I_{e}\right. \\
& \left.-T\left\{e^{e^{-\alpha \delta T \lambda_{0}}}-\frac{e^{\alpha \delta}\left(-1+e^{e^{-\alpha \delta T \lambda_{0}}}\right)}{\lambda_{0}}\right\}\right] \\
& -\frac{h D(p)}{T^{2} \lambda_{0}}\left[T e^{2 \alpha \delta}\left(-e^{-\alpha \delta} \lambda_{0}+e^{-\alpha \delta+e^{-\alpha \delta} T \lambda_{0}} \lambda_{0}\right)\right. \\
& \left.-e^{2 \alpha \delta}\left(-1-T e^{-\alpha \delta} \lambda_{0}+e^{-\alpha \delta+e^{-\alpha \delta} T \lambda_{0}}\right)\right]=0 .
\end{aligned}
$$


Proposition 2. When $T$ and $p$ are fixed, the total profit is concave with respect to $\alpha$.

Proof. The first- and second-order partial derivatives of the total profit with respect to $\alpha$ are as follows:

$$
\begin{aligned}
& \frac{\partial \mathrm{TP}_{1}(T, \alpha, p)}{\partial \alpha}=-\frac{D(p)}{T \lambda_{0}{ }^{2}}\left[\frac{\lambda_{0}{ }^{2}}{D(p)}-C e^{e^{-\alpha \delta} T \lambda_{0}} T \delta \lambda_{0}{ }^{2}\right. \\
& +\lambda_{0} C e^{\alpha \delta}\left(-1+e^{e^{-\alpha \delta} T \lambda_{0}}\right) \delta \\
& +2 e^{2 \alpha \delta} h \delta\left(-1+e^{e^{-\alpha \delta T \lambda_{0}}}-e^{-\alpha \delta} T \lambda_{0}\right) \\
& \left.+e^{2 \alpha \delta} h\left(e^{-\alpha \delta} T \delta \lambda_{0}-e^{e^{-\alpha \delta+\alpha \delta T \lambda_{0}}} T \delta \lambda_{0}\right)\right], \\
& \frac{\partial^{2} \mathrm{TP}_{1}(T, \alpha, p)}{\partial \alpha^{2}}=-\frac{1}{T}(a-b p)\left[-C e^{e^{-\alpha \delta} T \lambda_{0}} T \delta^{2}\right. \\
& +\frac{C e^{\alpha \delta}\left(e^{e^{-\alpha \delta} T \lambda_{0}}-1\right) \delta^{2}}{\lambda_{0}}+C e^{-\alpha \delta+e^{-\alpha \delta} T \lambda_{0}} T^{2} \delta^{2} \lambda_{0} \\
& +\frac{4 e^{2 \alpha \delta} h \delta^{2}\left(e^{e^{-\alpha \delta} T \lambda_{0}}-1-e^{-\alpha \delta} T \lambda_{0}\right)}{\lambda_{0}^{2}} \\
& +\frac{4 e^{2 \alpha \delta} h \delta\left(e^{-\alpha \delta} T \delta \lambda_{0}-e^{-\alpha \delta+e^{-\alpha \delta} T \lambda_{0}} T \delta \lambda_{0}\right)}{\lambda_{0}^{2}} \\
& \left.+\frac{e^{2 \alpha \delta} h\left(-e^{-\alpha \delta} T \delta^{2} \lambda_{0}-e^{-\alpha \delta+e^{-\alpha \delta} T \lambda_{0}} T \delta \lambda_{0}\left(-\delta-e^{-\alpha \delta} T \delta \lambda_{0}\right)\right)}{\lambda_{0}^{2}}\right] \\
& <0 \text {. }
\end{aligned}
$$

Consequently, for an optimum solution, it is necessary that $\partial \mathrm{TP}_{1}(T, \alpha, p) / \partial \alpha=0$

$$
\begin{aligned}
& \frac{\partial \mathrm{TP}_{1}(T, \alpha, p)}{\partial \alpha}=-\frac{D(p)}{T \lambda_{0}^{2}}\left[\frac{\lambda_{0}^{2}}{D(p)}-C e^{e^{-\alpha \delta} T \lambda_{0}} T \delta \lambda_{0}{ }^{2}\right. \\
& +\lambda_{0} C e^{\alpha \delta}\left(-1+e^{e^{-\alpha \delta} T \lambda_{0}}\right) \delta \\
& +2 e^{2 \alpha \delta} h \delta\left(-1+e^{e^{-\alpha \delta T \lambda_{0}}}-e^{-\alpha \delta} T \lambda_{0}\right) \\
& \left.+e^{2 \alpha \delta} h\left(e^{-\alpha \delta} T \delta \lambda_{0}-e^{e^{-\alpha \delta+\alpha \delta T \lambda_{0}}} T \delta \lambda_{0}\right)\right]=0 .
\end{aligned}
$$

Proposition 3. When $T$ and $\alpha$ are fixed, the total profit is concave with respect to $p$.
Proof. The first- and second-order partial derivatives of the total profit with respect to $p$ are as follows:

$$
\begin{aligned}
& \frac{\partial \mathrm{TP}_{1}(T, \alpha, p)}{\partial p}=(a-2 b p)-\frac{b}{T}\left[\frac{C}{\lambda(\alpha)}\left[e^{\lambda(\alpha) T}-1\right]\right. \\
& +\frac{h}{\lambda^{2}(\alpha)}\left[e^{\lambda(\alpha) T}-1-\lambda(\alpha) T\right]-I_{e} p\left(\frac{T^{2}}{2}\right) \\
& \left.+\frac{I_{p} C}{2}(T-M)^{2}\right]=0 \\
& \frac{\partial^{2} \mathrm{TP}_{1}(T, \alpha, p)}{\partial p^{2}}=-2 b+\frac{1}{2} b T I_{e}<0 .
\end{aligned}
$$

Hence, for an optimum solution, it is needed that $\partial \mathrm{TP}_{1}(T, \alpha, p) / \partial p=0$

$$
\begin{aligned}
& \frac{\partial \mathrm{TP}_{1}(T, \alpha, p)}{\partial p}=(a-2 b p)-\frac{b}{T}\left[\frac{C}{\lambda(\alpha)}\left[e^{\lambda(\alpha) T}-1\right]\right. \\
& +\frac{h}{\lambda^{2}(\alpha)}\left[e^{\lambda(\alpha) T}-1-\lambda(\alpha) T\right]-I_{e} p\left(\frac{T^{2}}{2}\right) \\
& \left.+\frac{I_{p} C}{2}(T-M)^{2}\right]=0 .
\end{aligned}
$$

Considering that (12), (14), and (16) are satisfied, thus the sufficient conditions are $\partial \mathrm{TP}_{1}(T, \alpha, p) / \partial T^{2}<0$, $\partial \mathrm{TP}_{1}(T, \alpha, p) / \partial \alpha^{2}<0$, and $\partial \mathrm{TP}_{1}(T, \alpha, p) / \partial p^{2}<0$. The Hessian determinant $H_{1}$ for sufficient conditions is given by

$$
\begin{aligned}
& H_{1} \\
& =\left|\begin{array}{lll}
\frac{\partial^{2} \mathrm{TP}_{1}(T, \alpha, p)}{\partial T^{2}} & \frac{\partial^{2} \mathrm{TP}_{1}(T, \alpha, p)}{\partial \mathrm{T} \partial} & \frac{\partial^{2} \mathrm{TP}_{1}(T, \alpha, p)}{\partial T \partial p} \\
\frac{\partial^{2} \mathrm{TP}_{1}(T, \alpha, p)}{\partial \alpha \partial T} & \frac{\partial^{2} \mathrm{TP}_{1}(T, \alpha, p)}{\partial \alpha^{2}} & \frac{\partial^{2} \mathrm{TP}_{1}(T, \alpha, p)}{\partial \alpha \partial p} \\
\frac{\partial^{2} \mathrm{TP}_{1}(T, \alpha, p)}{\partial p \partial T} & \frac{\partial^{2} \mathrm{TP}_{1}(T, \alpha, p)}{\partial p \partial \alpha} & \frac{\partial^{2} \mathrm{TP}_{1}(T, \alpha, p)}{\partial p^{2}}
\end{array}\right| \\
& <0 .
\end{aligned}
$$

Proposition 4. When $\alpha$ and $p$ are fixed, the total profit is concave with respect to $T$.

Proof. The first- and second-order partial derivatives of the total profit with respect to $T$ are as follows: 


$$
\begin{aligned}
\frac{\partial \mathrm{TP}_{2}(T, \alpha, p)}{\partial T} & \\
= & \frac{D(p)}{\lambda_{0}^{2} T^{2}}\left[\frac{\lambda_{0}^{2}(A+\alpha)}{D(p)}-p I_{e}\left(M-\frac{T}{2}\right) T \lambda_{0}^{2}+\lambda_{0} C e^{\alpha \delta}\left(-1+e^{e^{-\alpha \delta} T \lambda_{0}}\right)+e^{2 \alpha \delta} h\left(-1+e^{e^{-\alpha \delta} T \lambda_{0}}-e^{-\alpha \delta} T \lambda_{0}\right)\right] \\
& -\frac{D(p)}{T}\left[C e^{e^{-\alpha \delta} T \lambda_{0}}-I_{e} p\left(M-\frac{T}{2}\right)+\frac{p T I_{e}}{2}+\frac{e^{2 \alpha \delta} h}{\lambda_{0}}\left(e^{e^{-\alpha \delta}+e^{-\alpha \delta} T \lambda_{0}}-e^{-\alpha \delta}\right)\right], \\
\frac{\partial^{2} \mathrm{TP}}{2}(T, \alpha, p) & \partial T^{2} \\
= & \frac{D(p)\left(e^{e^{-\alpha \delta} T \lambda_{0}} h+p I_{e}+C e^{-\alpha \delta+e^{-\alpha \delta} T \lambda_{0}} \lambda_{0}\right)}{T} \\
& +\frac{2 D(p)\left[C e^{e^{-\alpha \delta} T \lambda_{0}}-p(M-T / 2) I_{e}+(1 / 2) p T I_{e}+e^{2 \alpha \delta} h\left(-e^{-\alpha \delta} \lambda_{0}+e^{-\alpha \delta+e^{-\alpha \delta} T \lambda_{0}} \lambda_{0}\right) / \lambda_{0}^{2}\right]}{T^{2}} \\
& -\frac{2 D(p)\left[A / D(p)+\alpha / D(p)-p(M-T / 2) T I_{e}+C e^{\alpha \delta}\left(e^{e^{-\alpha \delta} T \lambda_{0}}-1\right) / \lambda_{0}+e^{2 \alpha \delta} h\left(e^{e^{-\alpha \delta}} T \lambda_{0}-1-e^{-\alpha \delta} T \lambda_{0}\right) / \lambda_{0}^{2}\right]}{T^{3}}
\end{aligned}
$$

$<0$.

Thus, for an optimum solution, it is required that $\partial \mathrm{TP}_{2}(T$, $\alpha, p) / \partial T=0$

$$
\begin{aligned}
& \frac{\partial \mathrm{TP}_{2}(T, \alpha, p)}{\partial \alpha}=-\frac{D(p)}{\lambda_{0}^{2} T}\left[\frac{\lambda_{0}^{2}}{D(p)}-C e^{e^{-\alpha \delta} T \lambda_{0}} T \delta \lambda_{0}^{2}\right. \\
& +C e^{\alpha \delta}\left(-1+e^{e^{-\alpha \delta} T \lambda_{0}}\right) \delta \lambda_{0} \\
& +2 e^{2 \alpha \delta} h \delta\left(-1+e^{e^{-\alpha \delta T \lambda_{0}}}-e^{-\alpha \delta} T \lambda_{0}\right) \\
& +e^{2 \alpha \delta} h\left(e^{-\alpha \delta} T \delta \lambda_{0}-e^{\left.\left.e^{-\alpha \delta+\alpha \delta T \lambda_{0}} T \delta \lambda_{0}\right)\right]}\right. \\
& \frac{\partial^{2} \mathrm{TP}_{2}(T, \alpha, p)}{\partial \alpha^{2}}=-\frac{1}{T} D(p)\left[-C e^{e^{-\alpha \delta} T \lambda_{0}} T \delta^{2}\right. \\
& +\frac{C e^{\alpha \delta}\left(e^{e^{-\alpha \delta} T \lambda_{0}}-1\right) \delta^{2}}{\lambda_{0}}+C e^{-\alpha \delta+e^{-\alpha \delta} T \lambda_{0}} T^{2} \delta^{2} \lambda_{0} \\
& +\frac{4 e^{2 \alpha \delta} h \delta^{2}\left(e^{e^{-\alpha \delta} T \lambda_{0}}-1-e^{-\alpha \delta} T \lambda_{0}\right)}{\lambda_{0}^{2}} \\
& +\frac{4 e^{2 \alpha \delta} h \delta\left(e^{-\alpha \delta} T \delta \lambda_{0}-e^{-\alpha \delta+e^{-\alpha \delta} T \lambda_{0}} T \delta \lambda_{0}\right)}{\lambda_{0}^{2}}
\end{aligned}
$$$$
\frac{\partial \mathrm{TP}_{2}(T, \alpha, p)}{\partial T}=\frac{D(p)}{\lambda_{0}^{2} T^{2}}\left[\frac{\lambda_{0}^{2}(A+\alpha)}{D(p)}\right.
$$$$
-p I_{e}\left(M-\frac{T}{2}\right) T \lambda_{0}^{2}+\lambda_{0} C e^{\alpha \delta}\left(-1+e^{e^{-\alpha \delta} T \lambda_{0}}\right)
$$$$
\left.+e^{2 \alpha \delta} h\left(-1+e^{e^{-\alpha \delta} T \lambda_{0}}-e^{-\alpha \delta} T \lambda_{0}\right)\right]
$$$$
-\frac{D(p)}{T}\left[C e^{e^{-\alpha \delta} T \lambda_{0}}-I_{e} p\left(M-\frac{T}{2}\right)+\frac{p T I_{e}}{2}\right.
$$$$
\left.+\frac{e^{2 \alpha \delta} h}{\lambda_{0}}\left(e^{e^{-\alpha \delta}+e^{-\alpha \delta} T \lambda_{0}}-e^{-\alpha \delta}\right)\right]=0 .
$$

Proposition 5. When $T$ and $p$ are fixed, the total profit is concave with respect to $\alpha$.

Proof. The first- and second-order partial derivatives of the total profit with respect to $\alpha$ are as follows:

$\left.+\frac{e^{2 \alpha \delta} h\left(-e^{-\alpha \delta} T \delta^{2} \lambda_{0}-e^{-\alpha \delta+e^{-\alpha \delta} T \lambda_{0}} T \delta \lambda_{0}\left(-\delta-e^{-\alpha \delta} T \delta \lambda_{0}\right)\right)}{\lambda_{0}^{2}}\right]$ $<0$. 
As a result, for an optimum solution, it is obligatory that $\partial \mathrm{TP}_{2}(T, \alpha, p) / \partial \alpha=0$

$$
\begin{aligned}
& \frac{\partial \mathrm{TP}_{2}(T, \alpha, p)}{\partial \alpha}=-\frac{D(p)}{\lambda_{0}^{2} T}\left[\frac{\lambda_{0}^{2}}{D(p)}-C e^{e^{-\alpha \delta} T \lambda_{0}} T \delta \lambda_{0}^{2}\right. \\
& +C e^{\alpha \delta}\left(-1+e^{e^{-\alpha \delta} T \lambda_{0}}\right) \delta \lambda_{0} \\
& +2 e^{2 \alpha \delta} h \delta\left(-1+e^{e^{-\alpha \delta} T \lambda_{0}}-e^{-\alpha \delta} T \lambda_{0}\right) \\
& \left.+e^{2 \alpha \delta} h\left(e^{-\alpha \delta} T \delta \lambda_{0}-T \delta \lambda_{0} e^{-\alpha \delta+e^{-\alpha \delta} T \lambda_{0}}\right)\right]=0 .
\end{aligned}
$$

Proposition 6. When $T$ and $\alpha$ are fixed, the total profit is concave with respect to $p$.

Proof. The first- and second-order partial derivatives of the total profit with respect to $p$ are as follows:

$$
\begin{aligned}
& \frac{\partial \mathrm{TP}_{2}(T, \alpha, p)}{\partial p}=(a-2 b p)-\frac{b}{T}\left[\frac{C}{\lambda(\alpha)}\left[e^{\lambda(\alpha) T}-1\right]\right. \\
& \left.+\frac{h}{\lambda^{2}(\alpha)}\left[e^{\lambda(\alpha) T}-1-\lambda(\alpha) T\right]-I_{e} p T\left(M-\frac{T}{2}\right)\right] \\
& \frac{\partial^{2} \mathrm{TP}_{2}(T, \alpha, p)}{\partial p^{2}}=-2 b+b\left[M-\frac{T}{2}\right] I_{e}<0 .
\end{aligned}
$$

For that reason, for an optimum solution, it is mandatory that $\partial \mathrm{TP}_{2}(T, \alpha, p) / \partial p=0$ :

$$
\begin{aligned}
& \frac{\partial \mathrm{TP}_{2}(T, \alpha, p)}{\partial p}=(a-2 b p)-\frac{b}{T}\left[\frac{C}{\lambda(\alpha)}\left[e^{\lambda(\alpha) T}-1\right]\right. \\
& \left.+\frac{h}{\lambda^{2}(\alpha)}\left[e^{\lambda(\alpha) T}-1-\lambda(\alpha) T\right]-I_{e} p T\left(M-\frac{T}{2}\right)\right] \\
& \quad=0 .
\end{aligned}
$$

Considering that (19), (21), and (23) are satisfied, then the sufficient conditions are $\partial \mathrm{TP}_{2}(T, \alpha, p) / \partial T^{2}<0$, $\partial \mathrm{TP}_{2}(T, \alpha, p) / \partial \alpha^{2}<0$, and $\partial \mathrm{TP}_{2}(T, \alpha, p) / \partial p^{2}<0$. The Hessian determinant $\mathrm{H}_{2}$ for sufficient conditions is given by

$$
\begin{aligned}
& H_{2} \\
& =\left|\begin{array}{lll}
\frac{\partial^{2} \mathrm{TP}_{1}(T, \alpha, p)}{\partial T^{2}} & \frac{\partial^{2} \mathrm{TP}_{1}(T, \alpha, p)}{\partial \mathrm{T} \partial} & \frac{\partial^{2} \mathrm{TP}_{1}(T, \alpha, p)}{\partial \mathrm{T} \partial p} \\
\frac{\partial^{2} \mathrm{TP}_{1}(T, \alpha, p)}{\partial \alpha \partial T} & \frac{\partial^{2} \mathrm{TP}_{1}(T, \alpha, p)}{\partial \alpha^{2}} & \frac{\partial^{2} \mathrm{TP}_{1}(T, \alpha, p)}{\partial \alpha \partial p} \\
\frac{\partial^{2} \mathrm{TP}_{1}(T, \alpha, p)}{\partial p \partial T} & \frac{\partial^{2} \mathrm{TP}_{1}(T, \alpha, p)}{\partial p \partial \alpha} & \frac{\partial^{2} \mathrm{TP}_{1}(T, \alpha, p)}{\partial p^{2}}
\end{array}\right| \\
& <0 .
\end{aligned}
$$

Furthermore, the concavity of the total profit functions $\mathrm{TP}_{1}(T, \alpha, p)$ and $\mathrm{TP}_{2}(T, \alpha, p)$ is proved graphically (see Section 4). Using the mathematical results derived above, the following algorithm is proposed with the aim of determining the optimal values of $T, \alpha$, and $p$ for the inventory model.
Algorithm 7.

Step 1. Input all parameters.

Step 2. Determine the value of $T_{1}, \alpha_{1}$, and $p_{1}$ from (12), (14), and (16) and $T_{2}, \alpha_{2}$, and $p_{2}$ from (19), (21), and (23).

Step 3. Calculate $\mathrm{TP}_{1}{ }^{*}(T, \alpha, p), \mathrm{TP}_{2}{ }^{*}(T, \alpha, p)$, and $\mathrm{TP}_{2}{ }^{*}(M$, $\alpha, p)$ for the following cases: (1), (2), (3), or (4).

(1) If $M \leq T_{1}$ and $M \leq T_{2}$, then the optimal solution is $T^{*}=T_{1}$, and hence compute the total profit $\mathrm{TP}_{1}{ }^{*}\left(T^{*}, \alpha^{*}, p^{*}\right)=\mathrm{TP}_{1}{ }^{*}\left(T_{1}, \alpha, p\right)$ with (9) and go to Step 4 .

(2) If $M \geq T_{1}$ and $M \geq T_{2}$, then the optimal solution is $T^{*}=T_{2}$, and hence calculate the total profit $\operatorname{TP}^{*}\left(T^{*}, \alpha^{*}, p^{*}\right)=\operatorname{TP}_{2}{ }^{*}\left(T_{2}, \alpha, p\right)$ with $(10)$ and go to Step 4 .

(3) If $M \leq T_{1}$ and $M \geq T_{2}$, then the optimal solution is $T^{*}=M$, and hence determine the total profit $\mathrm{TP}^{*}\left(T^{*}, \alpha, p\right)=\mathrm{TP}_{2}{ }^{*}(M, \alpha, p)$ with (10) and go to Step 4 .

(4) If $T_{1} \leq M$ and $T_{2} \leq M$, then calculate $\mathrm{TP}_{1}\left(T_{1}, \alpha, p\right)$ and $\mathrm{TP}_{2}\left(T_{2}, \alpha, p\right)$ with (9) and with (10), respectively.

If $\mathrm{TP}_{2}\left(T_{2}, \alpha, p\right) \geq \mathrm{TP}_{1}\left(T_{1}, \alpha, p\right) \Rightarrow \mathrm{TP}(T, \alpha, p)=$ $\mathrm{TP}_{2}\left(T_{2}, \alpha, p\right)$, then the optimal value of $T$ is $T^{*}=T_{2}$, else $\operatorname{TP}(T, \alpha, p)=\operatorname{TP}_{1}\left(T_{1}, \alpha, p\right)$ and the optimal value of $T$ is $T^{*}=T_{1}$.

Step 4. Report the optimal solution for $T, \alpha, p$, and total profit $\operatorname{TP}(T, \alpha, p)$.

\section{Numerical Example}

This section presents and solves two numerical examples.

Example 1. Consider the following parameters: $A=\$ 80 /$ order, $a=250$ units, $b=8$ units, $C=\$ 4 /$ unit, $h=\$ 4 /$ unit/year, $I_{p}=0.2 /$ year, $I_{e}=0.8 /$ year, $M=0.6$ years, $\lambda_{0}=0.2$ units/year, and $\delta=20$.

By applying the proposed algorithm exhibited in Section 3 and with the help of the software Mathematica-9.0, the following optimal solution is obtained after several iterations: $T^{*}=0.324$ year, $\alpha^{*}=2.383 \$ /$ unit/year, and $p^{*}=$ 14.143 \$/unit.

Here, notice that $T=0.324$ years are less than $M=0.6$ years. The maximum total profit is $\mathrm{TP}_{1}{ }^{*}(T, \alpha, p)=1276.01$, the order size is $Q^{*}=44.946$ units, and the conditions $\partial^{2} \mathrm{TP}_{1}(T, \alpha, p) / \partial T^{2}=-5999.70, \partial^{2} \mathrm{TP}_{1}(T, \alpha, p) / \partial \alpha^{2}=$ $-1.25338<0$, and $\partial^{2} \mathrm{TP}_{1}(T, \alpha, p) / \partial p^{2}=-14.9632<0$. For the values of $T, \alpha$, and $p$, the determinant of Hessian matrix of $H_{1}$ is as follows: $\left|H_{1}\right|=-98695.40<0$. Therefore, the values of $T^{*}, \alpha^{*}$, and $p^{*}$ are optimal and maximize the total profit. Figures 2,3 , and 4 show the concavity of $\mathrm{TP}_{1}(T, \alpha, p)$ with respect to $\alpha, p$, and $\alpha$ and $p$, respectively. These figures demonstrate that the solution is a global optimal solution.

Example 2. Consider the following parameters: $A=\$ 100 /$ order, $a=250$ units, $b=8$ units, $C=\$ 6 /$ unit, $h=\$ 4 /$ unit/year, $I_{p}=0.2 /$ year, $I_{e}=0.8 /$ year, $M=0.2$ year, $\lambda_{0}=0.2$ units/year, and $\delta=20$.

By using the proposed algorithm given in Section 3 and with the help of the software Mathematica-9.0, the following optimal solution is found after some iterations: $T^{*}=$ 0.309 year, $\alpha^{*}=3.287 \$ /$ unit/year, and $p^{*}=12.515 \$ /$ unit. 


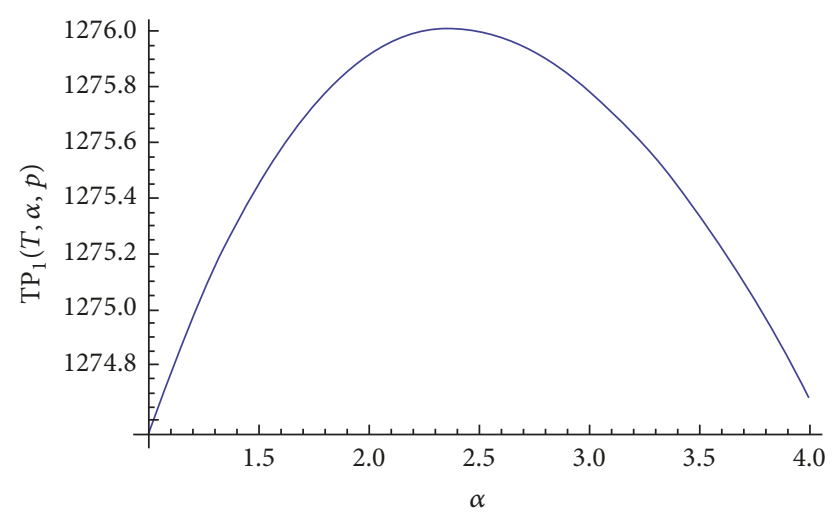

FIgURE 2: Concavity of $\operatorname{TP}_{1}(T, \alpha, p)$ with respect to $\alpha$.

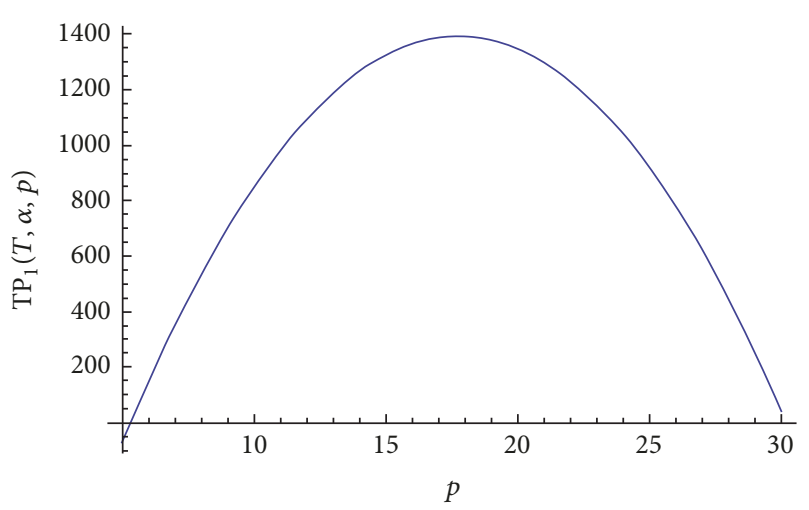

FIgURE 3: Concavity of $\operatorname{TP}_{1}(T, \alpha, p)$ with respect to $p$.

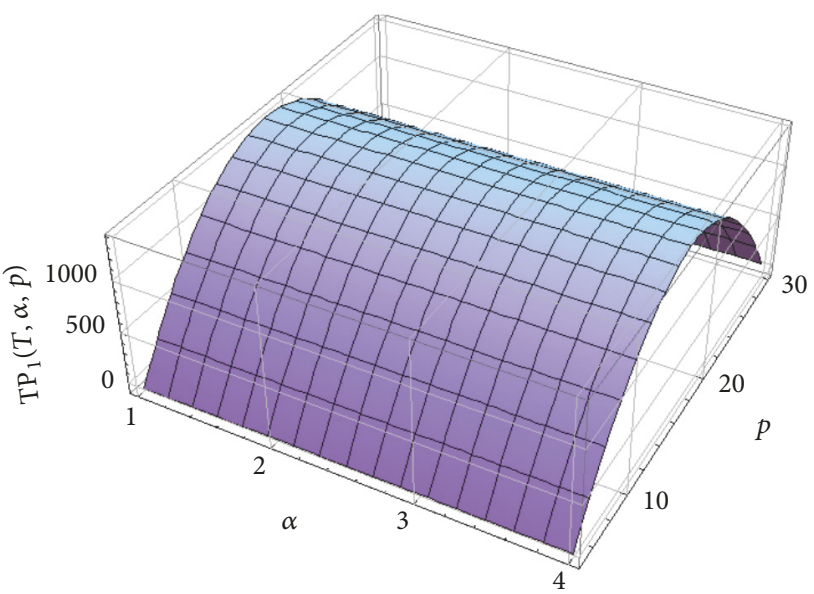

Figure 4: Concavity of $\operatorname{TP}_{1}(T, \alpha, p)$ with respect to $\alpha$ and $p$.

Here, note that $T=0.309$ years are greater than $M=0.2$ years. The maximum total profit is $\mathrm{TP}_{2}{ }^{*}(T, \alpha, p)=609.841$, the lot size is $Q^{*}=46.785$ units, and the conditions are $\partial^{2} \mathrm{TP}_{2}(T, \alpha, p) / \partial T^{2}=-190001<0, \partial^{2} \mathrm{TP}_{2}(T, \alpha, p) / \partial \alpha^{2}=$ $-1.30625<0$, and $\partial^{2} \mathrm{TP}_{1}(T, \alpha, p) / \partial p^{2}=-15.7088<0$.

For the values of $T, \alpha$, and $p$, the determinant of Hessian matrix of $\mathrm{H}_{2}$ is as follows: $\left|H_{2}\right|=-3.7674 \times 10^{6}<0$. Consequently, the values of $T^{*}, \alpha^{*}$, and $p^{*}$ are optimal and maximize the total profit. Figures 5, 6, and 7 demonstrate the

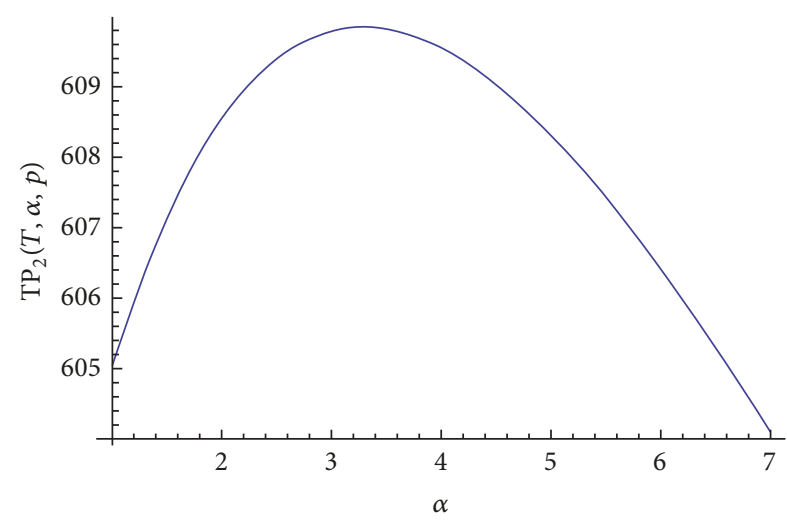

FIGURE 5: Concavity of $\mathrm{TP}_{2}(T, \alpha, p)$ with respect to $\alpha$.

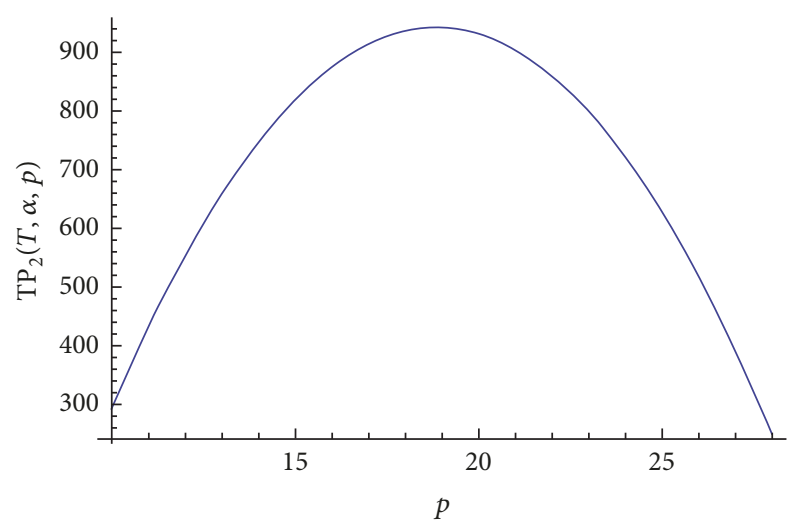

Figure 6: Concavity of $\mathrm{TP}_{2}(T, \alpha, p)$ with respect to $p$.

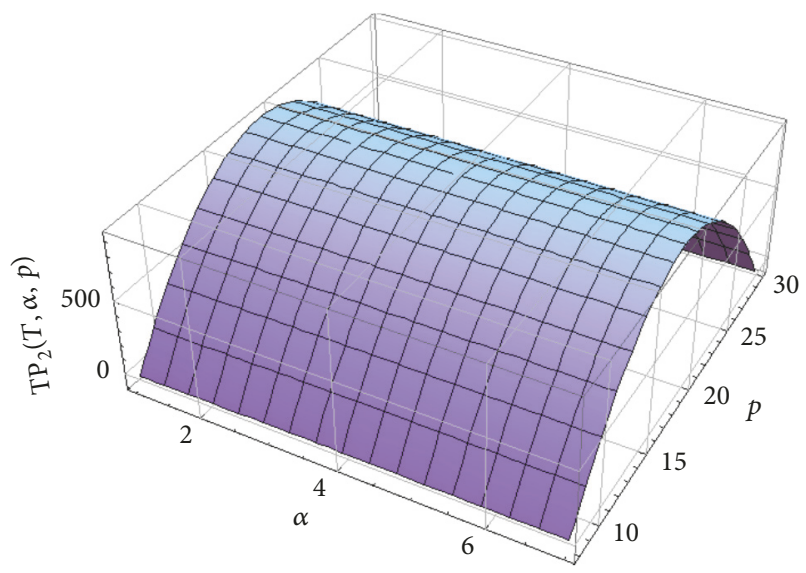

FIgURe 7: Concavity of $\mathrm{TP}_{2}(T, \alpha, p)$ with respect to $\alpha$ and $p$.

concavity of $\mathrm{TP}_{2}(T, \alpha, p)$ with respect to $\alpha, p$, and $\alpha$ and $p$, respectively. These figures confirm that the solution is a global optimal solution.

\section{Sensitivity Analysis}

This section studies the effects of changes in the inventory system parameters $\left(A, a, b, C, h, I_{p}, I_{e}, M, \lambda_{0}\right.$, and $\left.\delta\right)$ by changing of the parameters, taking one parameter at a time 
TABLE 2: Effect of changes of parameters on optimal solution for Example 1.

\begin{tabular}{|c|c|c|c|c|c|c|}
\hline Parameters & $\%$ change & $T^{*}$ & $\alpha^{*}$ & $p^{*}$ & $Q^{*}$ & $\mathrm{TP}_{1}^{*}(T, \alpha, p)$ \\
\hline \multirow{5}{*}{$A$} & $30 \%$ & 0.363374 & 2.96185 & 14.2406 & 49.9998 & 1266.68 \\
\hline & $15 \%$ & 0.344390 & 2.68839 & 14.1939 & 47.5481 & 1271.26 \\
\hline & $0 \%$ & 0.324339 & 2.38333 & 14.1433 & 44.9465 & 1276.01 \\
\hline & $-15 \%$ & 0.303001 & 2.03812 & 14.0877 & 42.1644 & 1280.93 \\
\hline & $-30 \%$ & 0.27607 & 1.56739 & 14.0142 & 38.6333 & 1286.86 \\
\hline \multirow{5}{*}{$a$} & $30 \%$ & 0.296699 & 2.49107 & 19.0606 & 51.7499 & 2578.27 \\
\hline & $15 \%$ & 0.309264 & 2.43699 & 16.606 & 48.3907 & 1880.09 \\
\hline & $0 \%$ & 0.324339 & 2.38333 & 14.1433 & 44.9465 & 1276.01 \\
\hline & $-15 \%$ & 0.342803 & 2.33074 & 11.6696 & 41.3988 & 766.148 \\
\hline & $-30 \%$ & 0.366018 & 2.28028 & 9.18029 & 37.7238 & 350.614 \\
\hline \multirow{5}{*}{$b$} & $30 \%$ & 0.318707 & 2.40211 & 10.2789 & 46.1674 & 714.264 \\
\hline & $15 \%$ & 0.321468 & 2.39273 & 11.9585 & 45.5598 & 961.768 \\
\hline & $0 \%$ & 0.324339 & 2.38333 & 14.1433 & 44.9465 & 1276.01 \\
\hline & $-15 \%$ & 0.327326 & 2.37393 & 17.1008 & 44.3273 & 1692.24 \\
\hline & $-30 \%$ & 0.330438 & 2.36453 & 21.3278 & 43.7018 & 2275.92 \\
\hline \multirow{5}{*}{ C } & $30 \%$ & 0.340667 & 3.31461 & 13.5291 & 48.735 & 1079.15 \\
\hline & $15 \%$ & 0.332418 & 2.86733 & 13.8361 & 46.8019 & 1179.81 \\
\hline & $0 \%$ & 0.324339 & 2.38333 & 14.1433 & 44.9465 & 1276.01 \\
\hline & $-15 \%$ & 0.319014 & 2.63483 & 14.3482 & 43.7508 & 1365.74 \\
\hline & $-30 \%$ & 0.308379 & 1.25346 & 14.7579 & 41.456 & 145.81 \\
\hline \multirow{5}{*}{$h$} & $30 \%$ & 0.236743 & 0.857263 & 13.8228 & 33.567 & 1083.083 \\
\hline & $15 \%$ & 0.273515 & 1.55704 & 13.9636 & 38.3852 & 1173.36 \\
\hline & $0 \%$ & 0.324339 & 2.38333 & 14.1433 & 44.9465 & 1276.01 \\
\hline & $-15 \%$ & 0.40066 & 3.40017 & 14.3936 & 54.5707 & 1400.42 \\
\hline & $-30 \%$ & 0.52838 & 4.74473 & 14.7992 & 70.0918 & 1569.93 \\
\hline \multirow{5}{*}{$I_{p}$} & $30 \%$ & 0.331227 & 2.49215 & 14.1469 & 45.8786 & 1282.11 \\
\hline & $15 \%$ & 0.327832 & 2.4388 & 14.145 & 45.4196 & 1279.09 \\
\hline & $0 \%$ & 0.324339 & 2.38333 & 14.1433 & 44.9465 & 1276.01 \\
\hline & $-15 \%$ & 0.320743 & 2.3256 & 14.1419 & 44.4585 & 1272.88 \\
\hline & $-30 \%$ & 0.31704 & 2.26545 & 14.1407 & 43.9553 & 1269.69 \\
\hline \multirow{5}{*}{$I_{e}$} & $30 \%$ & 0.33946 & 2.56897 & 14.4979 & 46.0505 & 1379.62 \\
\hline & $15 \%$ & 0.331642 & 2.47447 & 14.3142 & 45.4914 & 1335.50 \\
\hline & $0 \%$ & 0.324339 & 2.38333 & 14.1433 & 44.9465 & 1276.01 \\
\hline & $-15 \%$ & 0.317493 & 2.29533 & 13.9837 & 44.4161 & 1218.95 \\
\hline & $-30 \%$ & 0.311059 & 2.21026 & 13.8341 & 43.9007 & 1164.14 \\
\hline \multirow{5}{*}{$M$} & $30 \%$ & 0.346356 & 2.72841 & 14.1222 & 48.0147 & 1284.36 \\
\hline & $15 \%$ & 0.334823 & 2.55017 & 14.1343 & 46.4038 & 1280.56 \\
\hline & $0 \%$ & 0.324339 & 2.38333 & 14.1433 & 44.9465 & 1276.01 \\
\hline & $-15 \%$ & 0.315005 & 2.2309 & 14.1485 & 43.6575 & 1270.62 \\
\hline & $-30 \%$ & 0.306925 & 2.09605 & 14.1488 & 42.5525 & 1264.28 \\
\hline \multirow{5}{*}{$\lambda_{0}$} & $30 \%$ & 0.325465 & 3.05686 & 14.1462 & 44.8493 & 1275.75 \\
\hline & $15 \%$ & 0.324939 & 2.74214 & 14.1449 & 44.9509 & 1275.87 \\
\hline & $0 \%$ & 0.324339 & 2.38333 & 14.1433 & 44.9465 & 1276.01 \\
\hline & $-15 \%$ & 0.323639 & 1.96606 & 14.1415 & 44.9552 & 1276.17 \\
\hline & $-30 \%$ & 0.3228 & 1.4675 & 14.1394 & 44.989 & 1276.37 \\
\hline \multirow{5}{*}{$\delta$} & $30 \%$ & 0.325952 & 2.384942 & 14.1543 & 45.1516 & 1280.88 \\
\hline & $15 \%$ & 0.325284 & 2.38413 & 14.1496 & 45.0624 & 1276.50 \\
\hline & $0 \%$ & 0.324339 & 2.38333 & 14.1433 & 44.9465 & 1276.01 \\
\hline & $-15 \%$ & 0.322938 & 2.30928 & 14.1345 & 44.7898 & 1272.30 \\
\hline & $-30 \%$ & 0.320723 & 2.07688 & 14.1213 & 44.5685 & 1267.02 \\
\hline
\end{tabular}

and keeping the remaining parameters unchanged. Tables 2 and 3 present the results.

Based on the results of Tables 2 and 3, the following managerial insights are provided. (a) When the value of scaling factor (a) increases and other parameters' values are fixed, it can be observed that, for both cases, the optimal total profit per unit time $\mathrm{TP}_{i}{ }^{*}(T, \alpha, p)$; $i=1,2$, the optimal selling price $\left(p^{*}\right)$, and the optimal 
TABLE 3: Effect of changes of parameters on optimal solution for Example 2.

\begin{tabular}{|c|c|c|c|c|c|c|}
\hline Parameters & $\%$ change & $T^{*}$ & $\alpha^{*}$ & $p^{*}$ & $Q^{*}$ & $\mathrm{TP}_{2}{ }^{*}(T, \alpha, p)$ \\
\hline \multirow{5}{*}{$A$} & $30 \%$ & 0.353741 & 3.99375 & 12.3624 & 53.8351 & 503.202 \\
\hline & $15 \%$ & 0.332412 & 3.66378 & 12.4358 & 50.4186 & 554.753 \\
\hline & $0 \%$ & 0.309565 & 3.28746 & 12.515 & 46.7854 & 609.841 \\
\hline & $-15 \%$ & 0.284807 & 2.84892 & 12.6013 & 42.8798 & 669.313 \\
\hline & $-30 \%$ & 0.257541 & 2.32217 & 12.6967 & 38.6175 & 734.442 \\
\hline \multirow{5}{*}{$a$} & $30 \%$ & 0.24563 & 2.60305 & 17.585 & 45.6694 & 1817.05 \\
\hline & $15 \%$ & 0.273548 & 2.92294 & 15.0486 & 46.1036 & 1162.56 \\
\hline & $0 \%$ & 0.309565 & 3.28746 & 12.515 & 46.7854 & 609.841 \\
\hline & $-15 \%$ & 0.356499 & 3.71082 & 9.98532 & 47.6621 & 124.5162 \\
\hline & $-30 \%$ & 0.420237 & 4.21518 & 9.4614 & 48.8362 & 159.119 \\
\hline \multirow{5}{*}{$b$} & $30 \%$ & 0.34024 & 3.91769 & 8.76068 & 54.446 & 51.0562 \\
\hline & $15 \%$ & 0.325896 & 3.6252 & 10.3903 & 50.708 & 299.213 \\
\hline & $0 \%$ & 0.309565 & 3.28746 & 12.515 & 46.7854 & 609.841 \\
\hline & $-15 \%$ & 0.290785 & 2.88979 & 15.3985 & 42.6373 & 1016.37 \\
\hline & $-30 \%$ & 0.26891 & 2.40899 & 19.5319 & 38.2024 & 1581.20 \\
\hline \multirow{5}{*}{ C } & $30 \%$ & 0.311735 & 4.05493 & 11.5925 & 49.3265 & 220.946 \\
\hline & $15 \%$ & 0.310579 & 3.68945 & 12.0539 & 48.0355 & 420.428 \\
\hline & $0 \%$ & 0.309565 & 3.28746 & 12.515 & 46.7854 & 609.841 \\
\hline & $-15 \%$ & 0.308668 & 2.83729 & 12.9758 & 45.2796 & 789.217 \\
\hline & $-30 \%$ & 0.307852 & 2.32114 & 13.4365 & 44.4094 & 958.638 \\
\hline \multirow{5}{*}{$h$} & $30 \%$ & 0.296803 & 3.12304 & 12.4686 & 44.9767 & 577.478 \\
\hline & $15 \%$ & 0.302993 & 3.20371 & 12.4916 & 45.8539 & 593.516 \\
\hline & $0 \%$ & 0.309565 & 3.28746 & 12.515 & 46.7854 & 609.841 \\
\hline & $-15 \%$ & 0.316558 & 3.37453 & 12.5389 & 47.7763 & 626.478 \\
\hline & $-30 \%$ & 0.324019 & 3.4652 & 12.5634 & 48.8331 & 643.455 \\
\hline \multirow{5}{*}{$I_{e}$} & $30 \%$ & 0.279986 & 2.74691 & 12.7117 & 41.9136 & 654.146 \\
\hline & $15 \%$ & 0.293719 & 3.00535 & 12.6112 & 44.1856 & 630.984 \\
\hline & $0 \%$ & 0.309565 & 3.28746 & 12.515 & 46.7854 & 609.841 \\
\hline & $-15 \%$ & 0.32813 & 3.59871 & 12.4235 & 49.8067 & 591.033 \\
\hline & $-30 \%$ & 0.350298 & 3.94664 & 12.3371 & 53.386 & 574.957 \\
\hline \multirow{5}{*}{$M$} & $30 \%$ & 0.309362 & 3.24232 & 12.8288 & 45.9783 & 732.704 \\
\hline & $15 \%$ & 0.309453 & 3.26505 & 12.67 & 46.3848 & 671.106 \\
\hline & $0 \%$ & 0.309565 & 3.28746 & 12.515 & 46.7854 & 609.841 \\
\hline & $-15 \%$ & 0.309697 & 3.30954 & 12.3637 & 47.180 & 548.941 \\
\hline & $-30 \%$ & 0.309847 & 3.3313 & 12.2159 & 47.569 & 488.425 \\
\hline \multirow{5}{*}{$\lambda_{0}$} & $30 \%$ & 0.3106 & 3.96098 & 12.5114 & 46.9494 & 607.348 \\
\hline & $15 \%$ & 0.310117 & 3.64626 & 12.5131 & 46.8728 & 608.514 \\
\hline & $0 \%$ & 0.309565 & 3.28746 & 12.515 & 46.7854 & 609.841 \\
\hline & $-15 \%$ & 0.308922 & 2.87019 & 12.5172 & 46.6836 & 611.386 \\
\hline & $-30 \%$ & 0.308151 & 2.37164 & 12.5199 & 46.5615 & 613.242 \\
\hline \multirow{5}{*}{$\delta$} & $30 \%$ & 0.310117 & 3.03516 & 12.5193 & 46.7683 & 612.975 \\
\hline & $15 \%$ & 0.309907 & 3.16408 & 12.5173 & 46.7806 & 611.539 \\
\hline & $0 \%$ & 0.309565 & 3.28746 & 12.515 & 46.7854 & 609.841 \\
\hline & $-15 \%$ & 0.308994 & 3.3845 & 12.5122 & 46.7748 & 607.791 \\
\hline & $-30 \%$ & 0.307991 & 3.340288 & 12.5088 & 46.7397 & 605.29 \\
\hline
\end{tabular}

order quantity $\left(Q^{*}\right)$ increase, while the optimal length of replenishment cycle $\left(T^{*}\right)$ and the optimal preservation technology investment $\left(\alpha^{*}\right)$ fluctuate (increasing for Example 1 and decreasing for Example 2). This indicates that when the scaling factor $(a)$ is very large, the retailer will establish the selling price higher and will order more products to gain more profit. In addition, the retailer will also invest more funds into the improvement of preservation technology to 
decrease the item's deterioration, so the retailer can vend more products.

(b) When the price elasticity $(b)$ increases, the optimal cycle length $\left(T^{*}\right)$, the optimal selling price $\left(p^{*}\right)$, and the optimal total profit per unit time $\operatorname{TP}_{i}{ }^{*}(T, \alpha, p) ; i=1,2$, decrease, whereas the optimal preservation technology investment $\left(\alpha^{*}\right)$ and the optimal order quantity $\left(Q^{*}\right)$ increase. Apparently, as price elasticity $b$ increases, the retailer will reduce the selling price to prevent the demand rate from decreasing rapidly. And with a reduction in the selling price, the order quantity will decrease and the total profit per unit time will shrink significantly.

(c) When the value of the holding cost per unit time (h) increases, it can be noted that the optimal selling price $\left(p^{*}\right)$, the optimal profit per unit time $\operatorname{TP}_{i}^{*}(T, \alpha, p) ; i=1,2$, the optimal length of replenishment cycle $\left(T^{*}\right)$, preservation technology investment $\left(\alpha^{*}\right)$, and the optimal order quantity $\left(Q^{*}\right)$ decrease. This result reveals that while facing a higher holding cost, the enterprise will tend to reduce the optimal preservation technology investment, shorten the length of replenishment cycle, and order a smaller quantity each time for keeping inventory level as low as possible. From this sense, in order to enhance the competitiveness, the enterprise must pay more attention to storage process control to diminish the holding cost.

(d) Upon increasing the credit period $(M)$, the optimal total profit per unit time $\mathrm{TP}_{i}{ }^{*}(T, \alpha, p) ; i=1,2$, the optimal cycle length $\left(T^{*}\right)$, preservation technology investment $\left(\alpha^{*}\right)$, the optimal order quantity $\left(Q^{*}\right)$, and the optimal selling price $\left(p^{*}\right)$ decrease.

(e) With the increment in the value of the deterioration rate parameter $\left(\lambda_{0}\right)$, then preservation technology investment $\left(\alpha^{*}\right)$, the optimal selling price $\left(p^{*}\right)$, the optimal order quantity $\left(Q^{*}\right)$, and the optimal total profit per unit time $\mathrm{TP}_{i}{ }^{*}(T, \alpha, p) ; i=1,2$, decrease. This is an obvious result, because if the number of deteriorated items increases, then we have less profit.

(f) As the value of sensitive parameter of investment $(\delta)$ increases, the optimal total profit per unit time $\mathrm{TP}_{i}{ }^{*}(T, \alpha, p)$; $i=1,2$, the optimal cycle length $\left(T^{*}\right)$, preservation technology investment $\left(\alpha^{*}\right)$, and the optimal selling price $\left(p^{*}\right)$ increase, whereas the optimal order quantity $\left(Q^{*}\right)$ decreases.

(g) With increase in the value of interest earned rate $\left(I_{e}\right)$, the optimal total profit per unit time $\mathrm{TP}_{i}{ }^{*}(T, \alpha, p) ; i=$ 1,2 , the optimal cycle length $\left(T^{*}\right)$, preservation technology investment $\left(\alpha^{*}\right)$, and the optimal selling price $\left(p^{*}\right)$ increase, whereas the optimal order quantity $\left(Q^{*}\right)$ decreases, whereas an increase in the value of interest payable rate $\left(I_{p}\right)$ shows exactly opposite effect, which is a traditional result, and this validate the correctness of the proposed inventory model.

\section{Conclusion}

This paper investigates the retailer's replenishment policy for deteriorating items under trade credit policy when retailer invests money on preservation technology in order to reduce the deterioration rate. The main objective of this paper is to determine the optimal replenishment, selling price, and preservation technology investments strategies which maximize the total profit. There are numerous opportunities for future research work. For example, if the demand cannot be predicted, it is suggested to develop the inventory model with a stochastic demand. The proposed inventory model accepts that the demand only depends on the price under credit period and does not take customers' memories of the retailer's trade credit history into consideration. Since marketing and consumer behavior literature has empirically validated that the reference effect plays an important role in customer purchase decisions, hence, another possible extension of this work would need the incorporation of the reference effect into the proposed inventory model. Also, the effects of environmental issues on the suggested inventory model would be worth studying for future research.

\section{Conflicts of Interest}

The authors declare that there are no conflicts of interest regarding the publication of this paper.

\section{References}

[1] P. M. Ghare and G. F. Schrader, "A model for exponentially decaying inventory," Journal of Industrial Engineering, vol. 14, no. 5, pp. 238-243, 1963.

[2] P. H. Hsu, H. M. Wee, and H. M. Teng, "Preservation technology investment for deteriorating inventory," International Journal of Production Economics, vol. 124, no. 2, pp. 388-394, 2010.

[3] Y.-P. Lee and C.-Y. Dye, "An inventory model for deteriorating items under stock-dependent demand and controllable deterioration rate," Computers \& Industrial Engineering, vol. 63, no. 2, pp. 474-482, 2012.

[4] C.-Y. Dye and T.-P. Hsieh, "An optimal replenishment policy for deteriorating items with effective investment in preservation technology," European Journal of Operational Research, vol. 218, no. 1, pp. 106-112, 2012.

[5] C.-Y. Dye, "The effect of preservation technology investment on a non-instantaneous deteriorating inventory model," OMEGA The International Journal of Management Science, vol. 41, no. 5, pp. 872-880, 2013.

[6] J. Zhang, Z. Bai, and W. Tang, "Optimal pricing policy for deteriorating items with preservation technology investment," Journal of Industrial and Management Optimization, vol. 10, no. 4, pp. 1261-1277, 2014.

[7] G. Liu, J. Zhang, and W. Tang, "Joint dynamic pricing and investment strategy for perishable foods with price-quality dependent demand," Annals of Operations Research, vol. 226, no. 1, pp. 397-416, 2015.

[8] C. T. Yang, C. Y. Dye, and J. F. Ding, "Optimal dynamic trade credit and preservation technology allocation for a deteriorating inventory model," Computers and Industrial Engineering, vol. 87, pp. 356-369, 2015.

[9] Y.-C. Tsao, "Joint location, inventory, and preservation decisions for non-instantaneous deterioration items under delay in payments," International Journal of Systems Science, vol. 47, no. 3, pp. 572-585, 2016.

[10] U. Mishra, L. E. Cárdenas-Barrón, S. Tiwari, A. A. Shaikh, and G. Treviño-Garza, "An inventory model under price and stock dependent demand for controllable deterioration rate with shortages and preservation technology investment," Annals of Operations Research, vol. 254, no. 1-2, pp. 165-190, 2017. 
[11] S. K. Goyal, "Economic order quantity under conditions of permissible delay in payments," Journal of the Operational Research Society, vol. 36, no. 4, pp. 335-338, 1985.

[12] C. K. Jaggi and S. P. Aggarwal, "Credit financing in economic ordering policies of deteriorating items," International Journal of Production Economics, vol. 34, no. 2, pp. 151-155, 1994.

[13] S. P. Aggarwal and C. K. Jaggi, "Ordering policies of deteriorating items under permissible delay in payments," Journal of the Operational Research Society, vol. 46, no. 5, pp. 658-662, 1995.

[14] A. M. M. Jamal, B. R. Sarker, and S. Wang, "An ordering policy for deteriorating items with allowable shortage and permissible delay in payment," Journal of the Operational Research Society, vol. 48 , no. 8, pp. 826-833, 1997.

[15] K.-J. Chung, "A theorem on the determination of economic order quantity under conditions of permissible delay in payments," Computers \& Operations Research, vol. 25, no. 1, pp. 4952, 1998.

[16] A. M. M. Jamal, B. R. Sarker, and S. Wang, "Optimal payment time for a retailer under permitted delay of payment by the wholesaler," International Journal of Production Economics, vol. 66, no. 1, pp. 59-66, 2000.

[17] J.-T. Teng, "On the economic order quantity under conditions of permissible delay in payments," Journal of the Operational Research Society, vol. 53, no. 8, pp. 915-918, 2002.

[18] C.-T. Chang, "An EOQ model with deteriorating items under inflation when supplier credits linked to order quantity," International Journal of Production Economics, vol. 88, no. 3, pp. 307316, 2004.

[19] C.-T. Chang, S. K. Goyal, and J.-T. Teng, "On “An EOQ model for perishable items under stock-dependent selling rate and time-dependent partial backlogging" by Dye and Ouyang," European Journal of Operational Research, vol. 174, no. 2, pp. 923-929, 2006.

[20] Y.-F. Huang, "Economic order quantity under conditionally permissible delay in payments," European Journal of Operational Research, vol. 176, no. 2, pp. 911-924, 2007.

[21] K.-J. Chung and C.-K. Huang, "An ordering policy with allowable shortage and permissible delay in payments," Applied Mathematical Modelling, vol. 33, no. 5, pp. 2518-2525, 2009.

[22] K.-J. Chung and S.-D. Lin, "The inventory model for trade credit in economic ordering policies of deteriorating items in a supply chain system," Applied Mathematical Modelling, vol. 35, no. 6, pp. 3111-3115, 2011.

[23] K. V. Geetha and R. Udayakumar, "Optimal replenishment policy for deteriorating items with time sensitive demand under trade credit financing," American Journal of Mathematical and Management Sciences, vol. 34, no. 3, pp. 197-212, 2015.

[24] J.-J. Liao, "An EOQ model with noninstantaneous receipt and exponentially deteriorating items under two-level trade credit," International Journal of Production Economics, vol. 113, no. 2, pp. 852-861, 2008.

[25] C. K. Jaggi, S. K. Goyal, and S. K. Goel, "Retailer's optimal replenishment decisions with credit-linked demand under permissible delay in payments," European Journal of Operational Research, vol. 190, no. 1, pp. 130-135, 2008.

[26] J.-T. Teng, "Optimal ordering policies for a retailer who offers distinct trade credits to its good and bad credit customers," International Journal of Production Economics, vol. 119, no. 2, pp. 415-423, 2009.
[27] J.-T. Teng and C.-T. Chang, "Optimal manufacturer's replenishment policies in the EPQ model under two levels of trade credit policy," European Journal of Operational Research, vol. 195, no. 2, pp. 358-363, 2009.

[28] C.-T. Chang, L.-Y. Ouyang, J.-T. Teng, and M.-C. Cheng, "Optimal ordering policies for deteriorating items using a discounted cash-flow analysis when a trade credit is linked to order quantity," Computers \& Industrial Engineering, vol. 59, no. 4, pp. 770-777, 2010.

[29] C.-T. Chang, J.-T. Teng, and M.-S. Chern, "Optimal manufacturer's replenishment policies for deteriorating items in a supply chain with up-stream and down-stream trade credits," International Journal of Production Economics, vol. 127, no. 1, pp. 197-202, 2010.

[30] J.-T. Teng, I.-P. Krommyda, K. Skouri, and K.-R. Lou, "A comprehensive extension of optimal ordering policy for stockdependent demand under progressive payment scheme," European Journal of Operational Research, vol. 215, no. 1, pp. 97-104, 2011.

[31] J.-T. Teng, J. Min, and Q. Pan, "Economic order quantity model with trade credit financing for non-decreasing demand," Omega , vol. 40, no. 3, pp. 328-335, 2012.

[32] J.-T. Teng, H.-L. Yang, and M.-S. Chern, "An inventory model for increasing demand under two levels of trade credit linked to order quantity," Applied Mathematical Modelling, vol. 37, no. 14-15, pp. 7624-7632, 2013.

[33] K.-J. Chung, S.-D. Lin, and H. M. Srivastava, "The inventory models under conditional trade credit in a supply chain system," Applied Mathematical Modelling: Simulation and Computation for Engineering and Environmental Systems, vol. 37, no. 24, pp. 10036-10052, 2013.

[34] L.-Y. Ouyang and C.-T. Chang, "Optimal production lot with imperfect production process under permissible delay in payments and complete backlogging," International Journal of Production Economics, vol. 144, no. 2, pp. 610-617, 2013.

[35] L.-Y. Ouyang, C.-T. Yang, Y.-L. Chan, and L. E. CárdenasBarrón, "A comprehensive extension of the optimal replenishment decisions under two levels of trade credit policy depending on the order quantity," Applied Mathematics and Computation, vol. 224, pp. 268-277, 2013.

[36] S. Khanra, B. Mandal, and B. Sarkar, "An inventory model with time dependent demand and shortages under trade credit policy," Economic Modelling, vol. 35, pp. 349-355, 2013.

[37] S.-C. Chen, L. E. Cárdenas-Barrón, and J.-T. Teng, "Retailer's economic order quantity when the supplier offers conditionally permissible delay in payments link to order quantity," International Journal of Production Economics, vol. 155, pp. 284-291, 2013.

[38] J. Wu and Y.-L. Chan, "Lot-sizing policies for deteriorating items with expiration dates and partial trade credit to creditrisk customers," International Journal of Production Economics, vol. 155, pp. 292-301, 2014.

[39] S.-C. Chen and J.-T. Teng, "Inventory and credit decisions for time-varying deteriorating items with up-stream and downstream trade credit financing by discounted cash flow analysis," European Journal of Operational Research, vol. 243, no. 2, pp. 566-575, 2015.

[40] C. T. Chang, M. C. Cheng, and P. Y. Soong, "Impacts of inspection errors and trade credits on the economic order quantity model for items with imperfect quality," in Proceedings of the International Journal of Systems Science: Operations Logistics, vol. 3, pp. 34-48, 2016. 
[41] J. Wu, F. B. Al-Khateeb, J.-T. Teng, and L. E. Cárdenas-Barrón, "Inventory models for deteriorating items with maximum lifetime under downstream partial trade credits to creditrisk customers by discounted cash-flow analysis," International Journal of Production Economics, vol. 171, pp. 105-115, 2016.

[42] Y. Zhou, C. Chen, C. Li, and Y. Zhong, "A synergic economic order quantity model with trade credit, shortages, imperfect quality and inspection errors," Applied Mathematical Modelling, vol. 40, no. 2, pp. 1012-1028, 2016.

[43] S. Tiwari, L. E. Cárdenas-Barrón, A. Khanna, and C. K. Jaggi, "Impact of trade credit and inflation on retailer's ordering policies for non-instantaneous deteriorating items in a twowarehouse environment," International Journal of Production Economics, vol. 176, pp. 154-169, 2016.

[44] B. C. Giri and S. Sharma, "Optimal ordering policy for an inventory system with linearly increasing demand and allowable shortages under two levels trade credit financing," Operational Research, vol. 16, no. 1, pp. 25-50, 2016.

[45] C. K. Jaggi, S. Tiwari, and S. K. Goel, "Credit financing in economic ordering policies for non-instantaneous deteriorating items with price dependent demand and two storage facilities," Annals of Operations Research, vol. 248, no. 1-2, pp. 253-280, 2017.

[46] C. K. Jaggi, L. E. Cárdenas-Barrón, S. Tiwari, and A. A. Shafi, "Two-warehouse inventory model for deteriorating items with imperfect quality under the conditions of permissible delay in payments," Scientia Iranica, vol. 24, no. 1, pp. 390-412, 2017.

[47] G. C. Mahata and S. K. De, "Supply chain inventory model for deteriorating items with maximum lifetime and partial trade credit to credit-risk customers," International Journal of Management Science and Engineering Management, vol. 12, no. 1, pp. 21-32, 2017.

[48] C. Wu, Q. Zhao, and M. Xi, "A retailer-supplier supply chain model with trade credit default risk in a supplier-Stackelberg game," Computers \& Industrial Engineering, vol. 112, pp. 568575, 2017.

[49] D. Seifert, R. W. Seifert, and M. Protopappa-Sieke, "A review of trade credit literature: opportunities for research in operations," European Journal of Operational Research, vol. 231, no. 2, pp. 245-256, 2013.

[50] Z. Molamohamadi, N. Ismail, Z. Leman, and N. Zulkifli, "Reviewing the literature of inventory models under trade credit contact," Discrete Dynamics in Nature and Society, vol. 2014, Article ID 975425, 19 pages, 2014.

[51] Y. He and H. Huang, "Optimizing inventory and pricing policy for seasonal deteriorating products with preservation technology investment. of Industrial Engineering," Article ID, Article ID 793568, p. 1, 2013. 


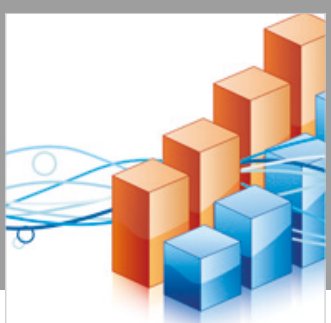

Advances in

Operations Research

\section{-n-m}
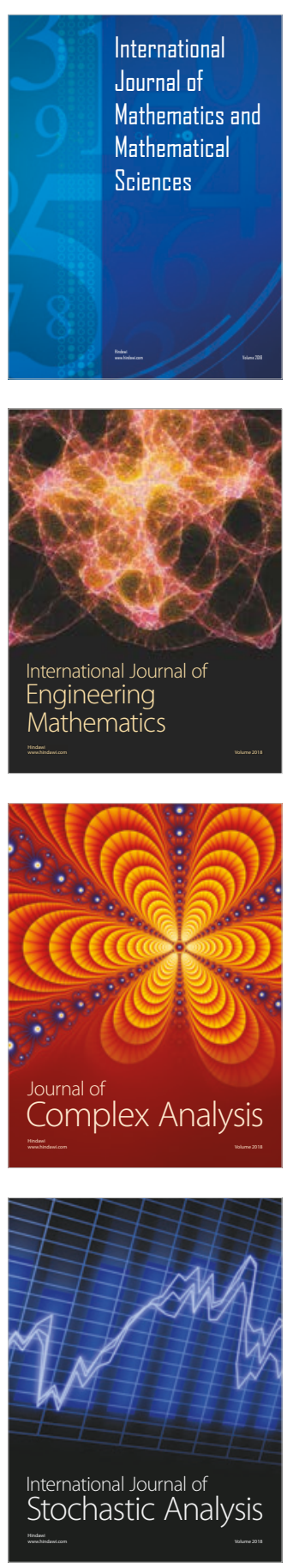
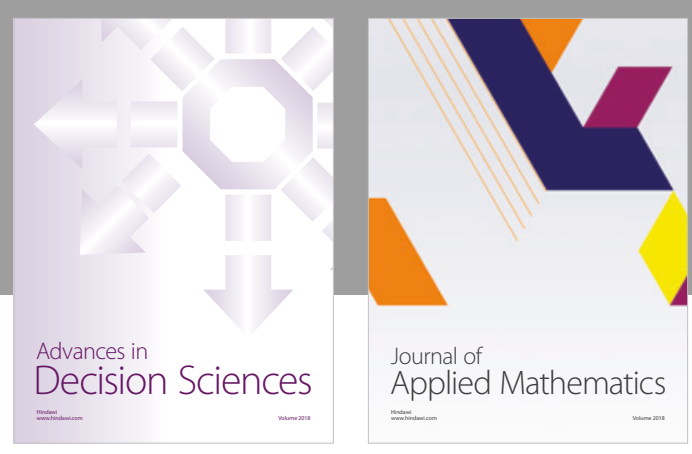

Journal of

Applied Mathematics
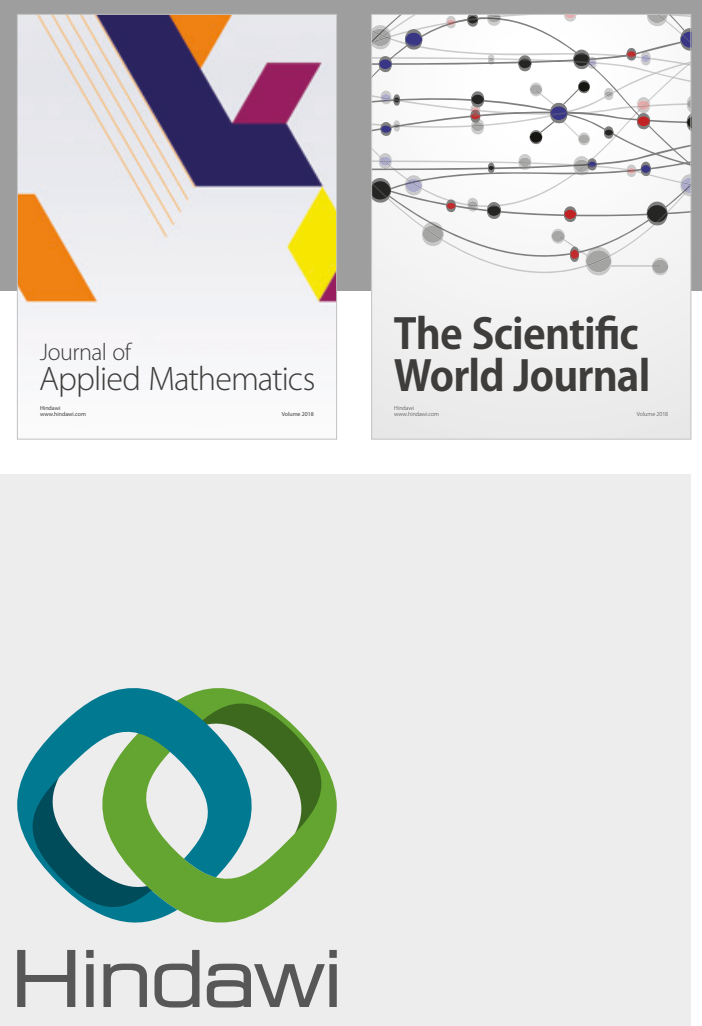

Submit your manuscripts at

www.hindawi.com

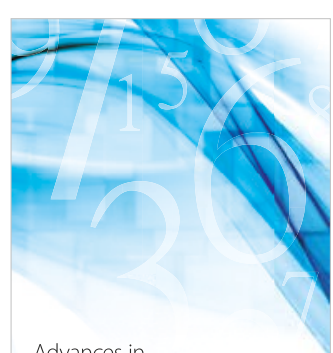

Advances in
Numerical Analysis
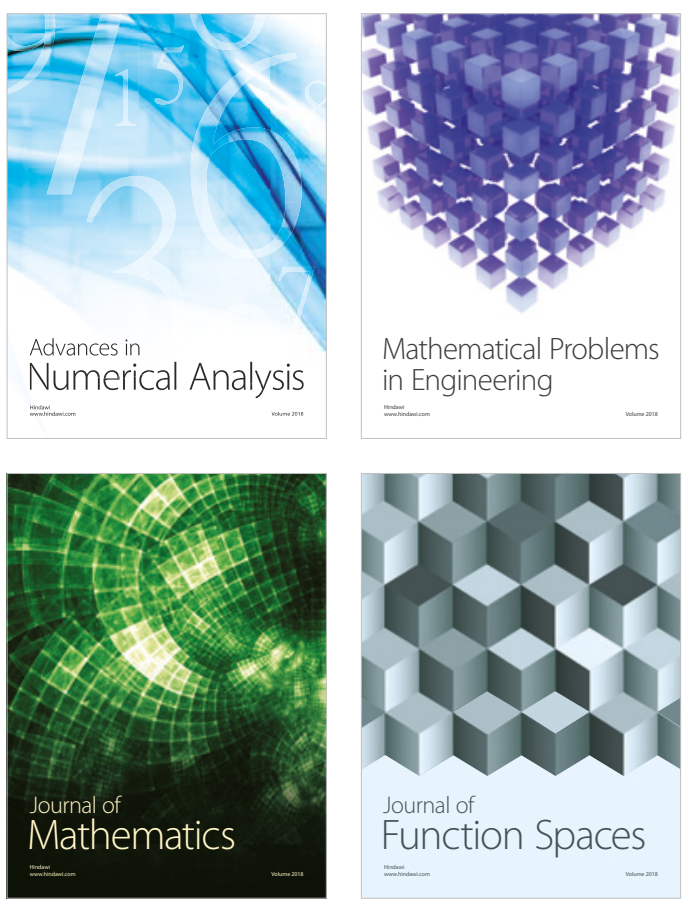

Mathematical Problems in Engineering

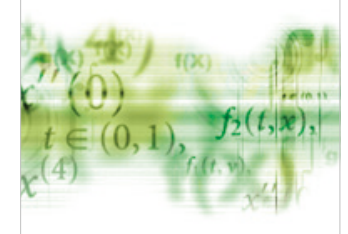

International Journal of

Differential Equations

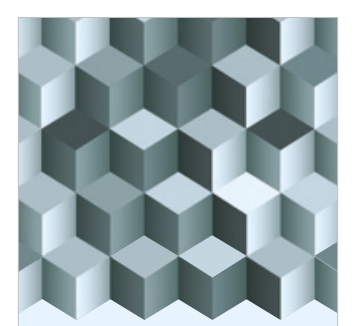

Journal of

Function Spaces

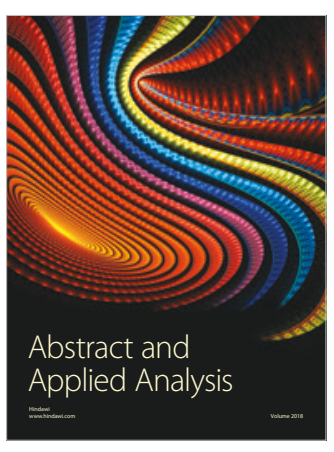

The Scientific

World Journal

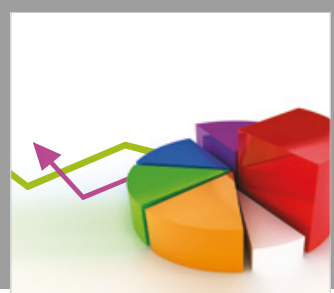

Journal of

Probability and Statistics
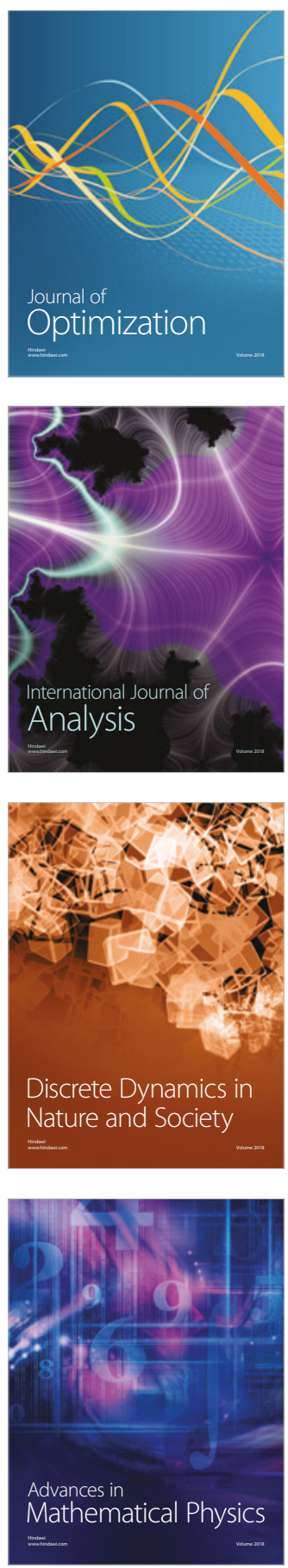